\title{
Dá prescrição da ação de investigação de paternidade
}

\author{
Lino de Morais Leme
}

1. Os argumentos em que se fundam os que sustentam ser imprescritivel a ação de investigação de paternidade, são os seguintes: a) o estado da pessoa não prescreve; b) as ações de estado não prescrevem.

2. Sem dúvida, o estado da pessoa não prescreve. Mas, quem tem o estado de filho? - O que tem, a seu favor, as presunções dos artigos 338 e 339 do Código Civil. Por isso ele estabelece, no art. 350: "A ação de prova de filiação legítima compete ao filho, enquanto viver, passando aos herdeiros, se ele morrer menor, ou incapaz". Essa a razão por que o legislador português declarou imprescritivel "o direito do filho legítimo a vindicar o estado que Ihe pertence" (Cod. Civ., art. 11, decreto n. 2, de 25-12-10, art. 14), ao passo que declarou prescritivel a ação para investigação de paternidade ilegítima.

Como diz Perdigão Malheiro, Comentário à lei n. 463, de 2 de setembro de 1847, p. 134: “. . em um povo civilizado e cristão, o casamento e a filiação legítima devem ser protegidos e favorecidos". É, aliás, o que estabelece a Constituição federal, no art. 124: “A família, constituida pelo casamento indissoluvel, está sob a proteção especial do Estado".

E foi por isso que, tendo estabelecido a citada presunção, procurou a lei facilitar, aos filhos nascidos do casamento, os meios de provar que são filhos legítimos. 
3. Poder-se-á pretender, com base no asserto de Crovis Bevilaqua (Teoria geral do direito, 2. ${ }^{a}$ ed., § 79) - que ว estado da pessoa diz respeito à ordem pública, é inalienavel, imprescritivel, e que, portanto, é imprescritivel a ação de investigação de paternidade.

Para logo se dá a resposta de que as legislações, com exceção do Código argentino, consideram prescritivel essa ação, e desbaratado fica o argumento.

São os seguintes os prazos da prescrição:

a) um ano após o nascimento - Cod. suiço, art. 308, devendo a ação ser intentada pela mãe ou pelo curador nomeado ao filho, desde que o mesmo nasceu ou que a mãe informou da gravidês;

b) um ano após a maioridade do filho - lei francesa de 16 de novembro de 1912, que substituiu o art. 340 do Cod. Civil, e igual prazo na Inglaterra e na Venezuela;

c) quatro anos após a maioridade, na Bélgica;

d) cinco anos após a maioridade do filho - lei uruguáia de 5 de setembro de 1914, e tambem na Holanda;

e) dez anos após a maioridade, no caso de sedução ou rapto, no Chile (Cod. Civ., art. 287);

f) até a morte do pái, salvo se se verificar durante a menoridade do investigante, em Honduras (Cod. Civ. de 1906, art. 287);

g) até um ano após o falecimento do pai, ou até quatro após a maioridade, se o filho era menor quando o pai faleceu, em Portugal (decr. n. 2, de 25 de dezembro de 1910, art. 37).

O Cod. alemão e o austríaco não teem um artigo especial sobre a prescrição dessa ação. Por isso, Caloyanni, Le droit de l'enfant dans le Code Civil suisse, en comparaison avec le droit des autres pays, 1928, dá-lhe o prazo de trinta anos, que é o da prescrição ordinária (p. 56), da mesma fórma que no direito brasileiro. 
4. O número anterior mostra o sentido em que devem ser entendidas as palavras de Clovis BeviláQua, o mestre dos mestres.

Confirma essa inteligência o art. 194 do Código Civil alemão: "O direito de exigir de outrem uma ação ou abstenção (reclamação) é submetido à prescrição. A reclamação que deriva de uma relação de família não está sujeita à prescrição, quando tem por fim o restabelecimento, para o futuro, de um ato de acordo com essas relações".

Fazendo a exegese desse artigo, diz Planck, citado por Carpenter, Manual do Cod. Civ., v., p. 199: "A exceção de que se trata só se refere àquelas ações que se destinam ao restabelecimento, para o futuro, de uma situação de fato correspondente aos direitos de família do sujeito ativo da ação".

Não se refere a afirmação de Clovis, evidentemente, aos filhos naturais não reconhecidos, que não tendo o estado de filho, pretendem adquiri-lo.

E' o próprio egrégio autor quem, por assim dizer, faz a exegese de suas palavras, quando escreve, no Cod. Civ., 5. ed., p. 340, no comentário ao art. 363: "Ora, das razões acima expostas resulta que a interpretação literal do art. 363, princípio, maximé atendendo-se ao prazo da ação, que é de trinta anos, por não lhe ter sido fixado outro mais curto, é contrária à boa razão".

Nas Soluções práticas de Direito, igualmente escreve: “... a ação, sendo pessoal e não tendo prazo próprio, somente no fim de trinta anos estará prescrita".

Quando se diz que o estado das pessoas é imprescritivel, quer-se dizer que se não perde por prescrição (arg. das palavras de Almeida Oliveira, A Prescrição, p. 67). Tambem não se adquirem por prescrição, e sim em virtude da lei ou de sentença.

Quem não possuir o estado de filho, precisa adquirí-lo - ou pelo reconhecimento voluntário, ou pelo reconhecimento forçado, que é a ação de investigação. E esta prescreve como todas as ações. 
5. Pretende-se ainda que as ações de estado não prescrevem, mas estão sujeitas aos prazos de caducidade. 0 objetivo do argumento é afastar essas ações dos prazos de prescrição editados pelo Código.

Já é alguma cousa o admitir-se que essas ações estão sujeitas a prazos de caducidade...

Ciarpenter (Manual Paulo de Lacerda, Da Prescrição, p. 192), depois de enumerar as ações de estado, escreve: “Destas ações, umas teem prescrições especiais de prazo breve, na conformidade do art. 178 do Código, e outras recaem na regra geral do art. 177 (prescrição trintenária)". A seguir, nessa página e na seguinte refere as ações que teem prescrições especiais de prazo breve, e escreve (p. 193 e seg.) :

“Assim o diz o próprio art. 166 do Código, que só veda ao juiz de conhecer de ofício a prescrição, quando se tratar de ações que protejam direitos patrimoniais, a saber, ações pessoais e reais, mas não ações de estado. A razão da lei facil é de ser percebida. Se à paz pública convém que não se revolvam velhas questões sôbre direitos patrimoniais (sejam obrigacionais, sejam reais), muito mais a ela deve importar que não se reacendam litígios sobre a posse de estado e, em geral, sobre as questões de estado das pessoas (Omissis). De tudo isso se infere a razão da lei, quando permitiu que nas ações de estado o juiz pudesse decretar de. ofício a prescrição: é que nelas os interesses da paz pública falam ainda mais alto do que nas ações que protegem os direitos patrimoniais".

Essa opinião de Carpenter é sufragada por Arí Azevedo Franco, Da prescrição extintiva, e pelos escritores que declaram prescritivel a ação de investigação de paternidade.

Se as ações de estado fossem imprescritiveis, não se justificariam os casos de prescrição do art. 178, na parte referente a essas ações, nem o do art. 208. 
E' de notar que o Código suiço, ao estabelecer, no art. 127, a regra sobre a prescrição das ações, se reporta a artigos do Código Civil, alguns referentes às ações de estado.

6. Deve falar-se em prescrição, ou em caducidade, relativamente às ações de estado?

Entendem alguns que a prescrição rege o campo econômico, e a caducidade o campo moral do direito. E incongruentemente falam de prescrição de ações que tutelam apenas interesses morais.

A técnica, de fato, introduziu uma diferença entre prescrição de ação e decadência de direito: aquela suscetivel de suspensão e interrupção; esta, não. Mas os efeitos são os mesmos: prescrita a ação, está.paralisado o direito; prescrito este, ou com a decadência, está paralizada a ação. Em D. R. havia diferença quanto aos efeitos - a prescrição da ação não aniquilava completamente o direito, pois subsistia a obrigação; em nosso direito, não.

Coelho da Rocha, Dir. Civ., § 454, define, com o Código da Austria: "Prescrição é a perda de um direito". Introduzida a diferença, passou ela a significar a perda da ação, reservado o vocábulo decadência para a perda do direito.

$O$ conceito de decadência aí está. Pode-se precisar que ela se verifica pelo inadimplemento de uma condição, ou de uma formalidade, no prazo estabelecido pela lei, como, em relação à prescrição, que ela se opera pelo não exercício $d a$ ação, em certo prazo. Como diz Pugliese, trata-se de um direito em via de formação, que, não exercido em certo prazo, morre antes de haver desenvolvido a sua eficácia.

A lei marca um prazo para ser feita a reclamação contra o lançamento, e o interessado deixou escoar-se o prazo: perdeu o direito. Estabelece a lei que o acionista de uma sociedade anônima deverá reclamar os seus dividendos em certo prazo, sob pena de comisso, e o acionista não os reclama no devido tempo: perdeu o direito. O comprador deixou correr o prazo sem utilizar-se do direito de resgate, que pactuara: perdeu-o. $\mathrm{O}$ condómino, em coisa indivisi- 
vel, não deposita o preço dentro em seis meses: perde o direito de haver para si a cousa vendida a estranho. Os herdeiros deixam de requerer o inventário no prazo de trinta dias: perde o direito de pagar sem multa o imposto causa mortis.

E' um erro pretender fazer-se uma enumeração casuística, como tentou Maximiliano, $O$ Direito, v. I, p. 41. Toda ciência tem princípios. Ou o conceito de decadência se regula por um princípio, ou ainda se encontra na fase empírica.

Esse princípio existe. Infelizmente, por falta de meditação, tem-se estabelecido a respeito confusão, a ponto de se entender que a prescrição é um instituto do direito das obrigações, enquanto que a decadência o é do direito de familia, como se não tivesse sentido a frase - prescrição da ação.

Essa a orientação seguida pelo Projeto de Código Civil argentino, que, de acordo com as idéias de BabiLoni, estabeleceu não prescreverem as ações inerentes ao direito de família. E, no art. 391, estabeleceu o prazo para se intentar a ação de nulidade de casamento; no art. 446, o da ação para impugnação da paternidade; no art. 467, a de impugnação de filiação; no 468, o da de investigação de paternidade ou de maternidade.

No entanto, tão forte é a força da lógica que, no art. 451, estabelece esse Código: "A faculdade de impugnar a legitimidade ou a filiação nos casos dos arts. 449 e 450 , não prescreve, nem se extingue por renúncia, embora se extingam os direitos econômicos adquiridos".

Se a prescrição é a extinção da ação, quando de ação se fala - de prescrição se trata. E a prova está no próprio Código e artigos citados.

A conclusão insofismavel é a que defendemos: a ação, qualquer que ela seja, está subordinada à prescrição; a lei, em certos casos, fixa um prazo para o exercício de um direito: aí se trata de caducidade.

E' a força da verdade, demonstrada pela lógica. 
7. Se quiséssemos sair do campo jurídico, outros argumentos teríamos a acrescentar.

E pois que assim limitámos o âmbito deste trabalho, vamos passar a indagar quando começa a prescrição da ação de investigação de paternidade.

Se o nascimento ocorreu na vigência do Código Civil, nenhuma divergência pode haver: o prazo começa a contar da data em que cessar a suspensão estabelecida no art. 169, n. I.

A dificuldade se apresenta em relação às pessoas nascidas anteriormente a esse Código. Essa a matéria que passa a ser examinada.

8. As Ordenações, liv. IV e tit. 99 , princ. e $\S 1 .^{\circ}$, davam ao filho direito a alimentos, mesmo que fossem espúrios e de qualquer outra condição. A propósito, Trigo Loureiro, Dir. civ. bras., lembra que o papa BenEdicto XIV, de Synodo Diocesana, liv. 13, cap. 23, decidiu que os Clérigos e Beneficiados eram obrigados a alimentar seus filhos ilegítimos não só pelo seu patrimônio como tambem pelos réditos eclesiásticos.

$\mathrm{E}$ as Ordenações, liv. IV, tit. 92, declaram haver direito sucessório - o filho ilegítimo, quando for descendente de peão, isto é, de plebeu não nobre.

A lei n. 463, de 2-9-1847, modificou o direito anterior, nos seguintes termos: "Art. 1. Aos filhos naturais dos nobres ficam estensivos os mesmos direitos hereditários, que pela Ord., L. 4. ${ }^{\circ}$, Tit. 92, competem aos filhos naturais dos plebeus. Art. $20^{\circ} \mathrm{O}$ reconhecimento do pái feito por escritura pública antes do seu casamento, é indispensavel para que qualquer filho natural possa ter parte na herança paterna, concorrendo ele com filhos legítimos do mesmo pái. Art. 3. ${ }^{\circ}$ A prova de filiação natural, nos outros casos, só se poderá fazer por um dos seguintes meios: escritura pública, ou testamento. Art. 4..$^{\circ}$ Ficam revogadas quaisquer disposições em contrário".

Com esses elementos, que representam o direito aplicavel, deve resolver-se a questão. 
9. Essa lei n. 463 pretendeu modificar o direito anterior, tanto em matéria de alimentos como na de reconhecimento dos fillhos naturais? TeIXeIRa de Freitas, Consolidaçâo das leis civís, 5. ${ }^{\mathrm{a}}$ ed., nota $\mathrm{n} .7$ ao art. 212, Rebouçis, Observação da Cons. das leis civis, pag. 62-66, pela afirmativa; pela negativa, Perdigão Malheiro, Comentário à lei $n$. 463 de 2 de setembro de 1874, pag. 14; CÂndido Mendes, Código Filipino, v. 2, pag. 987, nota 5; LAfayetTe, Direito de família, nota XII; TARQuínio DE Sousa Filho, Investigação da paternidade natural na ação de alimentos, in $O$ Direito, 28/161; João LuIz Alves, Da investigação da paternidade no direito pátrio, in O Direito, 80/161; JoÃo MonTEIRo, Universalizaçẫo do direito, p. 57 e nota; Estevão DE AlmeIDA, $M a-$ nual de Cod. Civ. bras., col. Paulo Lacerda, v. VI, pag. 150.

Perdigão Malheiro assim se manifesta: "A lei alterou a prova da filiação natural para a sucessão paterna, reduzindo-a a escritura pública e testamento, nos termos dos arts. $2 .^{\circ}$ e $3 .^{\circ}$; e, portanto, dependente da vontade do pái para esse fim. Não inovou porém, a legislação anterior quanto a essa prova para outros efeitos de direito; entre os quais os alimentos, e o estado. Nesta ação, pois, são admissiveis todas as provas, mesmo conjeturais, e nem se exige tanto rigor, como para a sucessão (omissis). Sendo assim, é consequência necessária que a sentença nela proferida, podendo fundar-se em outras provas, que não as únicas declaradas na lei, embora valha para o efeito de alimentos e estado do filho, não vale para a sucessão" (p. 14).

Retruca-lhe Teixeira de Freitas: "Não entendo esse art. 3. ${ }^{\circ}$ da lei de 1847 como o entendeu em seu coment. o sr. dr. Perdigão Malheiro (omissis). Declarando o art. 3. da citada lei, que a prova da filiação natural (note-se bem) - nos outros casos - só pode ser feita por escritura pública, ou testamento, é de evidencia que refere-se a mais de um caso, e portanto compreende alguma cousa mais do que o caso oposto ao excetuado no art. 2. ${ }^{\circ}$. Por outra, esse art. 3. não diz simplesmente que a filiação natural só pode ser provada por escritura pública ou testamento, quando não 
concorreram à herança paterna filhos legitimos do mesmo pái; o que diz é que - em todos os outros casos — a filiação natural deve ser provada por um dos mencionados meios" (p. 154-155).

Em a nota XII, de seu Direito de família, LAFAYETTE opinando a respeito, adota a opinião de Perdigão, pelos seguintes argumentos: $\left.1^{\circ}\right)$ A prova de filiação natural, para o efeito de sucessão, deve ser mais completa e rigorosa do que para alimentos; $20^{\circ}$ ) A inteligência em sentido contrário importaria, para os filhos naturais não reconhecidos, a privação do direito de pedir alimentos, e isso somente podia resultar de disposição expressa; $3^{\circ}$ ) A disposição do art. 3." a prova de filiação natural nos outros casos só se poderá fazer por um dos seguintes modos: "escritura pública ou testamento" não tem nem gramatical, nem logicamente o sentido que se lhe tem querido dar. A frase adversativa "nos outros casos" é contraposta à disposição do art. 2:. Este artigo prescreve que o reconhecimento, na hipótese a que alude (para os reconhecidos concorreram à herança com os legítimos do mesmo pai) não possa ser feito senão por escritura pública. "Nos outros casos" (art. 3. ${ }^{\circ}$ ) quer dizer a lei: nos casos em que os naturais não tenham de concorrer à herança com os legítimos, o reconhecimento pode ser feito por escritura pública ou tambem por testamento" (1).

O objetivo da lei n. 463 foi unicamente alterar a Ord. que se refere ao direito sucessório. $O$ projeto primitivo tinha apenas um artigo, que dizia - "Fica derrogada a Ord. L. 4. ${ }^{\circ}$ Tit. 92, na parte em que estabelece distinção entre. filhos naturais de nobres e de peões, em relação ao direito hereditário". A esse projeto, Sousa França ofereceu a seguinte emenda aditiva: "Para que o filho natural possa partilhar a herança de seu pai conjuntamente com os legitimos, será necessário que obtenha dele o reconhecimento

(1) Os dois últimos argumentos não escaparam a Tarquínro DE Sousa, em seu citado trabalho, de 1881 . 
por escritura pública outorgada em época anterior ao seu casamento. Nos outros casos se fará a prova de filiação natural por escritura pública, ou por testamento exclusivamente; e neste último caso será a herança considerada a todos os respeitos como legado, podendo o pai natural reduzí-lo e impor-lhe as condições que lhe aprouver no mesmo testamento". A justificação e a discussão do projeto e da emenda mostram que apenas do direito sucessório se tratou, não se tendo alterado, portanto, a Ord. do mesmo livro, tit. 99 .

10. Como observa João Luiz Alves, em seu citado trabalho, "quando parecia estar firmado o princípio da livre pesquisa da paternidade, porque a lei de 1847 só o revogou para o exclusivo fim da sucessão, nova controvérsia surgiu em virtude das disposições do art. $70^{\circ} \S 10^{\circ}$ alin. e art. $80^{\circ}$ do decr. de 24 de janeiro de 1890". Esse decreto fala em prova da filiação natural paterna - por confissão espontânea, pelo reconhecimento em escritura pública, ou no ato do nascimento, ou em outro documento autêntico oferecido pelo pai.

JoÃo Monteiro já entendera que o dispositivo do decreto n. 181, referindo-se a impedimentos matrimoniais, não se deve extender a outras relações. A esse argumento, originado do fim da lei, JoÃo LuIz acrescenta o de Tarquínio -LAFAyette, cm relação à lei de 1847 , de que se não pode dar à lei uma inteligência que priva de direito os filhos naturais -não reconhecidos, e de que, a entender-se revogado, pelo decr. de 1890 , o direito anterior, a respeito do reconhecimento forçado da filiação, força seria concluir pela revogação do diploma de 1847, quanto ao reconhecimento que confere direito sucessório aos filhos naturais - o que ninguem sustenta, e conclui: "... a investigação da paternidade foi sempre permitida em nosso direito, mediante qualquer gênero de provas. 
Depois de se referir à controvérsia, Estevão de Allmeida (2) assim conclui: "Do expendido resulta esta síntese do direito vigente antes do Código, quanto ao reconhecimento forçado: mediante qualquer gênero de prova, era permitida a investigação da paternidade, tanto dos filhos naturais como dos espúrios, restrita, porem, em seus efeitos, à obtenção de alimentos e do estado, depois da lei de 1847, e, vigorando esta, quanto à sucessão, tornado por ela dependente de voluntário reconhecimento do pái, limitado aos filhos naturais em espécie e feito só por escritura pública ou testamento".

Paulo de Lacerda, porém, sustentava, em 1906: "O decr. 181, de 24 de janeiro de 1890, ampliou os modos de reconhecimento da filiação natural paterna (omissis). E nada mais acrescentando, não alterou, senão pela ampliação dos modos de reconhecimento o direito vigente. $E$ isso, não que pelas fórmas de reconhecimento admitidas, alem daquelas dá lei de 1847, deixem de ser atribuidos direitos sucessórios, como diz o emérito Clovis, Direito da família, § 169; mas que elas são outras tantas portas abertas ao filho natural para entrar na família paterna sob o império e em toda a plenitude do direito existente ao tempo do decr. 181 de 1890, e até hoje inalterado". E reporta-se à interpretação de Coelho Rodrigues, autor da lei, na Revista mensal, 9/110.

Do que se expôs resulta não haver o decr. n. 181 revogado o direito anterior, com referência ao direito dos filhos naturais. Aliás, de suas próprias palavras — “... a filiação natural paterna tambem pode provar-se..." - se verifica que o objetivo foi ampliar os meios de prova.

11. A ação de investigação de paternidade é prejudicial, para as de alimentos e de petição de herança.

A ação de investigação de paternidade é uma ação pessoal, de estado, no direito de família puro. As ações de

(2) Manual do Cod. Civ., col. Paulo de Lacerda, v. VI, p. 150.

(3) Parecer in $O$ Direito, $100 / 457$. 
alimentos, de petição de herança, teem essa ação de estado como pressuposto. Não se admite ação de alimentos ou de petição de herança, sem que ou antes, ou na mesma ação. se vindique o estado de família.

Por isso, as ações de estado são chamadas prejudiciais. Sôbre elas, escreveram Correia Teles, Doutrina das ações, $\S 3 .^{\circ}$, e Joño Monteiro, especialmente na Doutrina das ações, ps. 55 e seguintes.

São deste os seguintes conceitos:

- "Não menos decisivo é o caso figurado no fr. 8, de agnoscendis et alendis (XXV, 2). Em ação de alimentos, o réu nega que é pai ou filho do autor: o juiz não deve dar ou negar os alimentos pedidos sem que primeiramente se prove ser o autor filho ou pai do réu" (p. 59).

- "Vindo a questão prejudicial com a contestação ao libelo, indubitavelmente a sentença, se ela proceder, lhe há de ligar o efeito lógico de deixar sem base a ação; e assim, consoante os princípios informativos do processo, com menor esforço se obterá o máximo resultado" (p. 60).

- E, citando a GLÜcK: "Em se tratando do estado de uma pessoa, não é possivel julgar dos direitos e obrigações que dele derivam, sem que antes se haja assegurado o estado mesmo; porquanto, da decisão sobre o estado depende contemporaneamente a de muitas outras que lhe são dependentes" (p. 62).

Nem pode haver dúvida que, à semelhança das questões prejudiciais, no processo penal, quando cumulada a ação de investigação à de alimentos ou à de petição de herança, não é possivel conceder aqueles, ou deferir esta, sem que previamente tenha o juiz se pronunciado sobre o estado da pessoa. Com efeito, como deferir a herança a alguem, como filho, sem preliminarmente ser apurado se o é?

Daí a decisão in Revista do Direito, 99/93: A ação de investigação de paternidade é prejudicial para a ação de petição de herança. Para poder exercitar esta ação, é mistér poder exercer a primeira, visto o carater prejudicial desta. A ação de petição de herança pode vir depois da de 
investigação, ou cumulada com esta; nunca, sózinha. Isso evidencia a dependência em que a petição da herança está da investigação.

Portanto, prescrita, a primeira ação, não poderá ser exercida a segunda.

12. Se o filho podia intentar a ação de investigação de paternidade anteriormente ao Código Civil, não pode a prescrição da mesma começar a correr da vigência dessa lei. Correrá a partir da data em que ele houver atingido a puberdade, nos termos das Ordenações, Livro IV, tit. 79, alin. 2, e de acôrdo com o ensinamento de Goelro da Rocha (4) : "Todas as obrigações, ou, o que vale o mesmo, todos os direitos, e ações correspondentes podem ser extintos pela extintiva, exceto aqueles que a lei declara imprescritiveis". E o prazo da prescrição das ações pessoais era de trinta anos, como se vê no mesmo tit. 79, citado, e como diz a ementa de ac. do Tribunal de Apelação de S. Paulo (5).

13. Assim se alicerçam as seguintes conclusões: tivel;

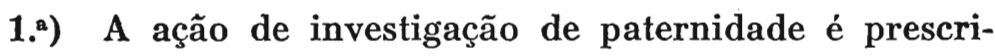

2. ${ }^{a}$ O prazo da prescrição, em relação aos nascimentos ocorridos anteriormente ao Código Civil, conta-se da data em que o filho atingiu a idade da puberdade legal.

(4) Instituições de dir. civ. port., v. 2, p. 43.

(5) Revista. dos Tribunais, 21/201. 